\title{
Who can assess HR performance in IT/IS projects: a review
}

\author{
António Silva, João Varajão, Carlos Sousa Pinto and Jorge Oliveira e Sá \\ Centro ALGORITMI, University of Minho, 4804-533 Guimarães, Portugal \\ a58889@alumni.uminho.pt, \{jev, csp, jos\}@dsi.uminho.pt
}

\begin{abstract}
Acting in markets characterized by a growing demand, organizations need to manage their human resources effectively and nowadays recognize that human resources (HR) are key elements to obtain success. In fact, organizations, by looking for operation optimization, have interest in enhancing the performance of human resources through systematic appraisals, by collecting and using information from individual and team performance. In the context of information technology/information systems (IT/IS) projects, the research that focuses on HR performance appraisal is scarce. To help fill this gap this paper presents a review of sources on performance information, which are applicable to these kind of projects.
\end{abstract}

Keywords: Performance Appraisal; Appraisal Scenarios; Human Resources; Projects; Information Technologies; Information Systems.

\section{Introduction}

Organizations need to enhance the performance of their human resources by conducting an effective and efficient management of those resources. In this context, the performance evaluation is emerging as an important component of the human resources management activity, bringing together different approaches and methods, which might contribute to improve the performance of organizations. With the evolution of human resource management, it has become clear that human performance needs not only to be planned regarding organizational objectives, but also to be assessed and oriented to achieve those objectives.

The appraisal of human resources performance is thus fundamental in virtually all projects and organizations, and the case of Information Technologies/Information Systems (IT/IS) projects is no exception. These projects "have maintained an unfortunate reputation when it comes to success", since most of them exhibit serious problems in terms of meeting the scope, the time or the budget [1]. The success of IT/IS projects depends on rigorous project management processes in which aspects such as, the involvement of top management and customers, the definition of clear objectives and requirements, an effective management of human resources, among others, are critical [2].

Although everyone recognizes that the performance appraisal is essential to the management of human resources and a key aspect to the success of organizations and 
projects, there is not much research work with focus on the particular case of IT/IS projects. Aiming to contribute to fill this gap, this paper reviews sources of performance information, which may be successfully applied in IT/IS projects.

In the next section, we discuss the importance of performance evaluation. The third section describes the different types of IT/IS projects. In the fourth section, we present several sources on performance information identified in the literature. Finally, some concluding remarks and future work ideas are presented.

\section{The importance of performance appraisal}

The performance appraisal is a measurement and systematic comparison of individual, group and organizational variables, supported in a framework of skills and/or pre-defined objectives. Performance comes from the competencies (knowledge, experience and attitudes) inherent to the individuals, from their personality, their motivation, interpersonal relations, the work environment and the characteristics of projects and organizations [3].

Ultimately, performance is the result of work [4,5] and the appraisal aims to diagnose, evaluate and improve gradually such performance [6]. Performance appraisal intends to always answer two questions [7]: "what things are not going as they should?" and "what things need to be improved?".

In organizations it is usual to implement performance measurement processes to assist, at the organizational level, in administrative decisions (e.g., definition of remunerations, promotions, compensations, transfers and dismissals) and, at the individual level, to allow people to recognize the assessment that is made about their performance (positive or negative), but also to allow the evaluator to advise the employee regarding his improvement. This evaluation process may confirm the quality of the recruitment and the process of employee selection, and allows to verify the effectiveness of paid training, and to improve the team and the organizational environment $[4,8]$.

Performance evaluation should be carried out with particular caution, since employees dissatisfied with the results of their assessment processes may leave the organization. The turnover of human resources involved in IT/IS projects may represent a loss of valuable knowledge and organizational experience, accumulated over the years, with direct and immediate implications in projects where such resources are involved. This fact also implies the appearance of new costs associated with the recruitment and training of replacement personnel, probably delaying the completion of projects [9]. The successful implementation of the evaluation processes requires the commitment, the involvement and the active participation of all stakeholders, implying a process of communication, openness, and orientation to improvement, being necessary that all stakeholders receive continuous feedback about their performance [10]. The performance evaluation is mostly associated to measuring processes. To implement a performance evaluation process it is necessary to reflect carefully on the objectives to achieve and the procedures to follow, defining when, who and how to intervene in the evaluation [11]. The performance appraisal process should be based on the close proximity of the appraiser and the assessed: this 
proximity enables a better performance appraisal and provides a fast and effective feedback to the assessed [5].

\section{Information Technology/Information Systems Projects}

There have been increasing levels of investment in IT/IS by organizations over the last few years, implying significant changes in the way of doing business [12, 13].

There are several types of IT/IS projects intended to respond to the different needs of organizations [14]. Cadle \& Yeates [15] typify IT/IS projects in eight categories, namely: software development; outsourcing; consultancy and business analysis assignments; system enhancement; disaster recovery; infrastructure implementation; package implementation; systems migration projects.

Software development arises from the need to build software applications (e.g., Web applications [16]. In this type of project skills are required to analyze, specify, build, test and implement new software for customers. On the one hand, products may be developed based on an idea or a need recognized in the market, in which the products are developed to prospective clients that are unknown until the product is marketed (called Commercial off-the-shelf software development). On the other hand, software can be developed according to the specific needs of each client (custom software development). Software development projects can be performed internally (insourcing), externally (outsourcing) using a contractor to provide the software, or by both internal and external teams (selective sourcing) [17].

The consultancy and business analysis assignments projects arises from the need to investigate a business problem or propose solutions using IT/IS. This type of project typically involves activities such as the analysis of the technological and/or organizational system (as the object of intervention), and the definition of the As-Is situation, in order to further identify and present possible improvement aspects taking into account the best business practices (Ought-To-Be situation). Finally, the processes are validated with the organization's management in order to define their further implementation ( $\mathrm{To} B e$ situation).

The system enhancement and disaster recovery projects have their origins in the need to repair, improve or add functionality to a system to meet (new) market requirements, or to comply with new law and regulation standards, for example and, typically, the team's effort is to maintain and support existing systems. If the team has to improve and develop new features, one of the difficulties that arises is to keep the existing system in operation while adding improvements/features, since there is the risk of damaging existing well-functioning system components.

Infrastructure projects emerges from the need to introduce or replace hardware. The entire life-cycle of these types of projects is similar to the life-cycle of a software development project.

The package implementation projects arises from the need to implement configurable commercial software products. Today, organizations acquire integrated management systems (commonly known as Enterprise Resource Planning - ERP systems), in the form of commercial packages, to support most of their processes [13], to manage their resources (materials, people or equipment) and integrate existing 
information systems into a single system. The evolution of technology has changed the way new information systems are developed - from the traditional custom development solutions to the aggregation of off-the-shelf, ready to use components, thus, significantly reducing costs and development times. In these type of projects, it is common to execute activities such as the consulting and analysis of business processes, configuration/parameterization of the systems and the development/adaptation of parts not covered by the software package.

System migration projects are necessary when the current systems are no longer supported or supportable. The activities necessary to perform these projects are to define the strategies to be adopted for the implementation and the conversion of data (in case it is needed), training the end-users and putting the new system in operation.

\section{Sources of performance information}

Given the importance of IT/IS projects, it is essential, as in other areas, the implementation of systematic processes of human resources performance assessment. In this section, we present various sources of performance information, which can be applied to IT/IS projects.

It is essential to define who should participate in the HR performance appraisal process. Usually, the appraisal by Supervisor (downward assessment) is the most widely used in organizations. However, it is important to avoid implementing an HR performance appraisal in a superficial way and with a one-side only perspective. Thus, many times there is a need to use other sources of HR performance appraisal for IT/IS development projects.

In Fig. 1, the main sources of performance information are identified, which are described in the following sections.

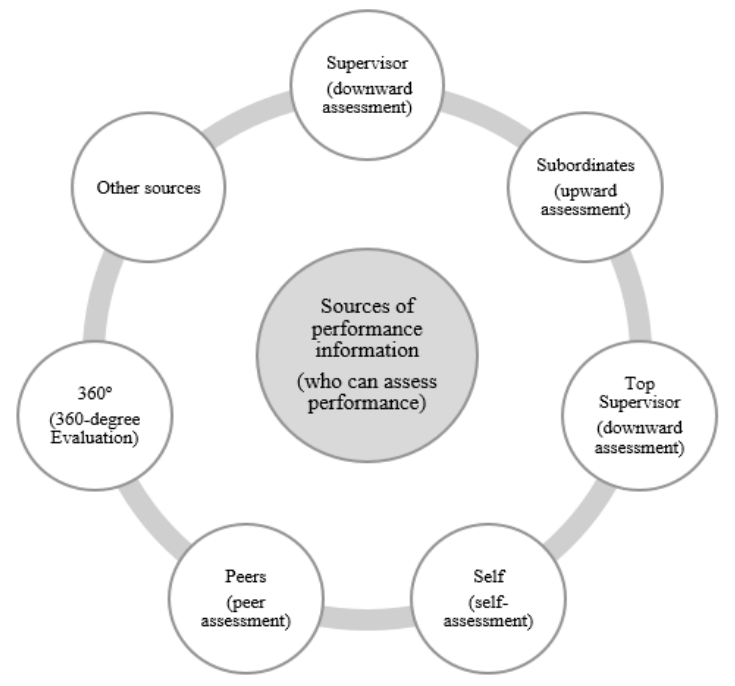

Fig. 1. Sources of performance information 


\subsection{Supervisor}

Generally, organizations legitimize the Supervisor to appraise their Subordinate. Fig. 2 illustrates the assessment by the employee's immediate Supervisor (downward assessment).

This source is relevant for administrative purposes (e.g., definition of salary range, promotions, demotions, transfers, layoffs and assignment of bonuses) and continues to be, in many organizations, the only HR performance appraisal source of information. Usually, the Supervisor has more information about the Subordinate's performance, because the Supervisor defines and manages with the Subordinate the goals to be achieved, and the Supervisor is responsible to advise and to support the Subordinate to facilitate the execution of their tasks [18]. This HR performance information source is a one-side only perspective and this appraisal is more prone to errors, because other performance appraisal perspectives are missing. This performance appraisal scenario becomes particularly complex when the assessed functions are interdependent.

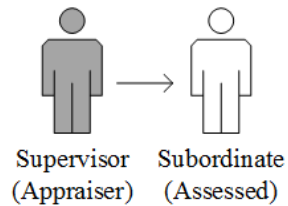

Fig. 2. Supervisor (downward assessment)

\subsection{Subordinates}

The assessment by Subordinates is presented in Fig. 3. Also known as "upward assessment", it is an appraisal carried out by Subordinates to report the performance of the Supervisor, in terms of communication skills, provision of correct resources for achieving the goals, guidance and motivation, etc. [18]. This scenario is not so much used because employees do not know exactly their Supervisor's tasks and responsibilities, or Subordinates may not make a true and sincere appreciation of the performance of his Supervisor because Subordinates could be afraid of negative consequences that may arise (in the case of unfavorable appraisal). Another limitation arises from the fact that this appraisal source possibly removes legitimate power in leadership. Therefore, directly observable behavioral aspects should be evaluated, such as the way the Supervisor performs its function and the relationship between Supervisor, Subordinates and teams.

In such cases, the assessed (the supervisor) should only receive information about the average of assessments carried out by subordinates, resulting in confidentiality of information. This appraisal scenario requires greater interaction among stakeholders, reinforcing team spirit and promoting the improvement of supervisor performance.

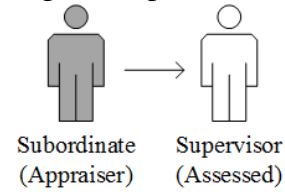

Fig. 3. Subordinates (upward assessment) 


\subsection{Top Supervisor}

In the assessment by the Top Supervisor (downward assessment), depicted in Fig. 4, the Supervisor of the appraiser (denominated Top Supervisor) may be involved by two different ways in the performance appraisal process. On the one hand, he can be involved by giving their approval on the appraisal made by his Subordinate (Supervisor). On the other hand, he can directly carry out the appraisal. Typically, this assessment occurs when the organization intends to compare employees for administrative purposes, e.g., to identify potential candidates for a promotion [19]. This scenario avoids the occurrence of leniency error (this arises when the appraiser is very biased to classify the assessed above the midpoint of the appraisal scale) and severity (minimizing the possibility of the assessed to be penalized or favored, due to the fact that its appraiser would be more or less severe).

However, the Top Supervisor could be unaware of the assessed work, because the Top Supervisor is not in direct contact with the assessed. This can enhance the mistake of "first impression" and "personal projection (this error occurs when the appraiser tends to do a performance appraisal as his similarity or the similarity of someone he knows)".

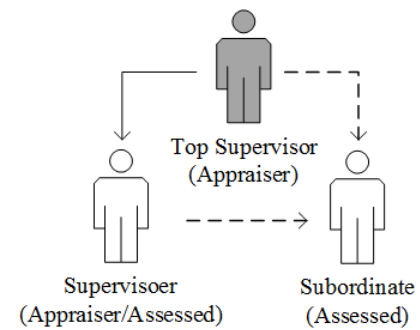

Fig. 4. Top Supervisor (downward assessment)

\subsection{Self}

The self-assessment, as illustrated in Fig. 5, allows the employee to do a self-appraisal in order to inform their strengths and weaknesses [20]. It is used for development purposes and for combination with other performance sources, in order to overcome performance appraisal errors. The self-appraisal enables the involvement of the employee in the performance appraisal process, ensuring the identification of his own capabilities, needs, individual goals and aspects to improve, and allows to establish plans of action and re-establish goals for the future. Generally, this could increase the possibility of the employee to accept the performance appraisal results, and the perception that he is treated with dignity and respect. However, employees can exaggerate and overvalue their performance (or even minimize or undervalue their performance) enhancing conflicts between appraiser and assessed due to disagreement with the performance appraisal given by the first, and this may call into question the relationship between the employee and his supervisor. Therefore, the self-appraisal should be validated with rigorous and objective data regarding the performance of the assessed. 


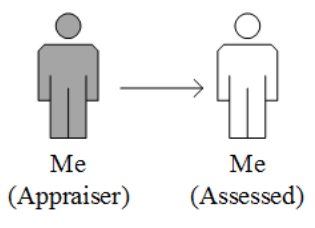

Fig. 5. Self (self-assessment)

\subsection{Peers}

Peer assessment is used for development purposes and consists of teammates performance appraisal (colleagues from same work area or having the same hierarchical level) and be assessed by them, because all work closely together and are in a privileged position to observe each other's performance (see Fig. 6).

This source of information is especially used in situations where teamwork is dominant and when it has a high degree of interdependence between tasks to be performed. One of the advantages of peer appraisal comes from the circumstance of teammates having more opportunities to contact and watch each other than supervisors. This enables the gathering of information about contribution, behavior and relationship of the assessed in the team. However, there is the possibility that the assessed will not be very receptive to be criticized by colleagues and will not have a good reaction to results of the peer appraisal. Another limitation is due to the fact that there could exist relations of friendship or rivalry between the assessed and their peers, which may distort the results of the appraisal. Therefore, the peer appraisal should be introduced with caution so to not create incompatibilities between teammates, neither distort the appraisal results [18].

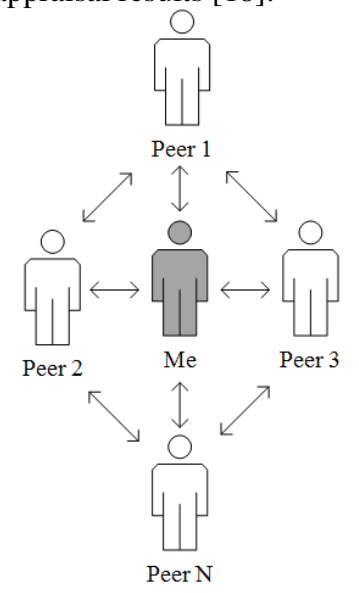

Fig. 6. Peers (peer assessment)

$4.5360^{\circ}$

Also known as "feedback from multiple sources", 360-degree Evaluation is used for development purposes and is characterized by being made an appraisal of all 
employees that maintain some interaction with the assessed employee, as depicted in Fig. 7. Thus, the appraisal refers to an individual involved in a general context and spans multiple perspectives due to the project participation of supervisors, colleagues, subordinates and stakeholders. The appraisal is done in a circular fashion (all are appraisers), hence the designation of the 360-degree Evaluation.

The employee is assessed by all the people who affect and are affected by their performance in the organization, and the appraisal results are confidential, i.e., the employee is unaware of who assessed him and only has access to the final appraisal results of his performance.

It enhances the improvement of employee performance, identifying which aspects of the performance need to be improved, and also enhances employee awareness about what behaviors are valued by the organization. This type of appraisal increases objectivity (due to the use of various perspectives) and the amount of information about performance aspects observed by stakeholders, which means that many difficulties are overcome and distortions are corrected due to the use of multiple sources [21]. However, there are some limitations associated with this appraisal scenario, namely: negative reactions due to the implementation of an appraisal of this nature due to requiring feedback from multiple sources; disagreements between the various appraisers about the assessed, this can be understood as an indicator about reliability of the appraisal performance; disagreements can generate distrust about the appraisal process and promised anonymity; disagreements due to appraisal anonymity enabling appraisers to conspire in giving an inadequate appraisal; and the performance appraisal process is very complex, time consuming and expensive [22].

In fact, in order to make the 360-degree Evaluation, a new perspective was included recently, in which the "external consultant" role emerges with the goal of analyzing the results of the applied performance appraisal tools, preventing the emergence of appraisal errors and enhancing confidence in the appraisal process. This variant of the 360-degree Evaluation is denominated the 450-degree Evaluation [23].

To a more complete performance appraisal, these sources can also be combined with sources of other nature as, for instance: evaluation of work deliverables; project management reports; benchmarks; etc.

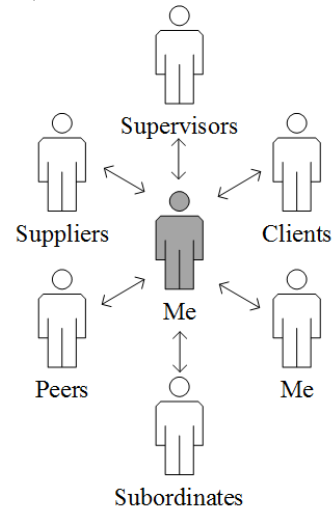

Fig. 7. 360-degree Evaluation 


\section{Conclusions}

There are several sources of information for human resources performance appraisal, including Supervisor (downward assessment), Subordinates (upward assessment), Top Supervisor (downward assessment), Self (self-assessment), Peers (peer assessment), 360-degree Evaluation and Other sources. Matching the use of appropriate performance appraisal tools with the goals of a project, in a given context, enables the collection of relevant information and act to optimize the HR performance.

These different sources are applicable to IT/IS projects, however there is scarce research in IT/IS field with focus on this subject. To help fill this gap this paper discusses the importance of performance appraisal in IT/IS projects and carries out a review of the main sources of appraisal.

This work also proposes new subjects for future research since there are several questions that justify the search for answers such as, "how often should a performance appraisal be done during a project?", "what techniques of performance appraisal should be used?", "what kind of feedback is more useful to subordinates?", "do IT/IS projects require the use of different appraisal approaches?", among others.

The work presented in this paper can be useful for researchers, for project managers and for organizations, since it describes, in a structured way, different sources of information that can be useful for performance appraisal in IT/IS projects.

\section{Acknowledgements}

This work has been supported by COMPETE: POCI-01-0145-FEDER-007043 and FCT Fundação para a Ciência e Tecnologia within the Project Scope: UID/CEC/00319/2013.

\section{References}

1 J. Varajão, C. Dominguez, P. Ribeiro, and A. Paiva, "Critical Success Aspects in Project Management: Similarities and Differences Between the Construction and the Software Industry," Teh. Vjesn. Gaz., vol. 21, no. 2, pp. 583-589, 2014.

2 R. Colomo-Palacios, I. González-Carrasco, J. L. López-Cuadrado, A. Trigo, and J. E. Varajão, "I-Competere: Using applied intelligence in search of competency gaps in software project managers," Inf. Syst. Front., vol. 16, no. 4, pp. 607-625, 2014.

3 K. R. Murphy and J. Cleveland, Understanding performance appraisal: Social, organizational, and goal-based perspectives. SAGE Publications, Inc., 1995.

4 H. J. Bernardin, J. S. Kane, S. Ross, J. Spina, and D. L. Johnson, "Performance Appraisal Design, Development and Implementation," in Handbook of Human Resource Management, G. R. Ferris, S. D. Rosen, and D. T. Barnum, Eds. Cambridge: Wiley-Blackwell, 1995.

5 M. K. Sanyal and S. B. Biswas, "Employee Motivation from Performance Appraisal Implications: Test of a Theory in the Software Industry in West Bengal (India)," in Procedia Economics and Finance, vol. 11, no. 14, Elsevier, 2014, pp. 182-196.

6 C.-L. Tai, "The Relationships Among Leader Social Support, Team Social Support, Team Stressors and Team Performance," Elsevier, vol. 57, pp. 404-411, 2012. 
7 J. Nemiro, M. Beyerlein, and S. Beyerlein, The Handbook of High-Performance Virtual Teams, 1st ed. San Francisco: Jossey-Bass, 2008.

8 M. R. Carrell, N. F. Elbert, and R. D. Hatfield, Human Resource Management: Strategies for Managing a Diverse and Global Workforce, 6th ed. Houghton Mifflin Harcourt, 2000.

9 L. G. Pee, A. Kankanhalli, G. W. Tan, and G. Z. Tham, "Mitigating the impact of member turnover in information systems development projects," IEEE Trans. Eng. Manag., vol. 61, no. 4, pp. 702-716, 2014.

10 C. Fletcher, "Performance appraisal and management: The developing research agenda," J. Occup. Organ. Psychol., vol. 74, no. 4, pp. 473-487, 2001.

11 R. Freeman and R. Lewis, Planning and implementing assessment. Kogan Page, 1998.

12 N. Gonzálvez-Gallego, F.-J. Molina-Castillo, P. Soto-Acosta, J. Varajão, and A. Trigo, "Using integrated information systems in supply chain management," Enterp. Inf. Syst., vol. 9, no. 2, pp. 210-232, 2015.

13 A. Trigo, J. Varajão, N. Figueiredo, and J. Barroso, "Information Systems and Technology Adoption by the Portuguese Large Companies," in EMCIS 2007 - European and Mediterranean Conference on Information Systems (Vol. 2007), Valencia, 2007.

14 A. Trigo, J. Varajão, J. Barroso, P. Soto-Acosta, F. Molina-Castillo, and N. GonzalvezGallego, "Enterprise Information Systems Adoption in Iberian Large Companies: Motivations and Trends," Manag. Adapt. Interv. People Enterp. Inf. Syst., pp. 204-228, 2011.

15 J. Cadle and D. Yeates, Project Management for Information Systems, 5th Ed. Essex: Pearson, Prentice Hall, 2008.

16 A. Silva, F. Moreira, and J. Varajão, "The Enterprise 2.0 Concept: Challenges on Data and Information Security,” Knowl. Manag. Inf. Syst. E-Learning, Sustain. Res., vol. 111, pp. 363-368, 2010.

17 J. Varajao, A. Trigo, N. Figueiredo, J. Barroso, and J. B. Cruz, "Information systems services outsourcing reality in large Portuguese organisations," Int. J. Bus. Inf. Syst., vol. 4, no. 1 , p. $125,2009$.

18 R. N. Lussier and J. R. Hendon, "Human Resource Management: Functions, Applications, and Skill Development," 2nd Ed., Singapore: SAGE Publications, Inc., 2016, p. 712.

19 M. Harris and J. Schaubroeck, "A meta-analysis of self-supervisor, self-peer, and peersupervisor ratings," Pers. Psychol., vol. 41, no. 1, pp. 43-62, Mar. 1988.

20 G. Thornton, "Psycometric Properties of Self-Appraisals of Job Performance," Pers. Psychol., vol. 33, no. 2, pp. 263-271, 1980.

21 M. S. Saiyadain, Human Resources Management, 4th ed. New Delhi: Tata McGraw-Hill Publishing Companies Limited, 2009.

22 C. L. Facteau, J. D. Facteau, L. C. Schoel, J. E. A. Russell, and M. L. Poteet, "Reactions of leaders to 360-degree feedback from subordinates and peers," Leadersh. Q., vol. 9, no. 4, pp. 427-448, 1998.

23 J. Ayoubi, "450-degree feedback: extending the value and power of 360," Personnel Today, 2012. [Online]. Available: http://www.personneltoday.com/hr/450-degree-feedbackextending-the-value-and-power-of-360/. [Accessed: 11-Oct-2015]. 